\title{
Perbandingan Pengaruh Self Correction dan Task Oriented Exercise dengan Klapp Exercise terhadap Derajat Skoliosis Siswa SMP dengan Skoliosis Idiopatik Tipe C
}

\author{
Nia Kurniawati ${ }^{1}$, Noorhana Fadilla ${ }^{2}$, Mohammad Ali ${ }^{3}$ \\ 1,2,3Politeknik Kesehatan Kemenkes Jakarta III
}

Email:nnia_physio@yahoo.com

Submitted: 16-11-2019, Revised: 03-12-2019, Accepted: 03-12-2019

DOI: https://doi.org/10.36082/qik.v13i2.78

\begin{abstract}
Abstrak
Latar Belakang: Skoliosis merupakan gangguan disfungsi dan deformitas tulang belakang, dengan ciri terdapat kurva lateral yang berkaitan dengan rotasi transversal dan sagital. Self-correction \& task oriented exercise merupakan metode latihan dengan memberikan tugas fungsional spesifik yang melibatkan fungsi neuromusculoskeletal. Klapp Exercise berfokus pada gerakan penguluran dan penguatan postur yang mengalami masalah menyebabkan skoliosis. Tujuan Penelitian: Untuk mengetahui perbedaan pengaruh Self-correction \& Task Oriented Exercise dengan Klapp Exercise terhadap derajat skoliosis siswa SMP dengan skoliosis idiopatik tipe C. Metode penelitian: Penelitian menggunakan quasi eksperimental dengan desain two group pre test post test. Populasi penelitian yaitu siswa Kelas 7 dan 8 dengan sampel sebanyak 22 orang yang terbagi dalam 2 kelompok. Pengukuran derajat rotasi skoliosis menggunakan skoliometer untuk data sebelum dan sesudah intervensi.Intervensi dilakukan sebanyak 10 kali, pengulangan selama 3 kali seminggu. Hasil: Uji perbedaan derajat skoliosis sebelum dan sesudah intervensi Self-correction \& Task Oriented Exercise dan Klapp Exercisemenggunakan uji paired t-test, didapatkan nilai $p$ 0,0001. Hasil uji perbedaan pengaruh intervensi yang diberikan dilakukan dengan uji independent t-test, didapatkan nilai $p$ 0,699.Kesimpulan: Terdapat pengaruh
\end{abstract}

bermakna pada kedua intervensi. Tidak ada perbedaan pengaruh antarakedua intervensi .

Kata Kunci :Skoliosis, Self correction, Task Oriented Exercise, Klapp Exercise
Abstract
Background: Scoliosis is a spinal dysfunction, characterized by lateral curve with transverse and sagittal rotations. Self-correction \& task oriented exercise providing specific functional tasks involving neuromusculoskeletal function. Klapp Exercise focuses on the stretching and strengthening of postures that are having problems causing scoliosis. Objective: To know the differences about Self-correction \& Task Oriented Exercise with Klapp Exercise to decreased the degree of scoliosis with AIS. Methods: The study used quasi experimental with two group pre test post test design with 22 samples divided into 2 groups. Measurement used scoliometer for before and after intervention data. Intervention done as much as 10 times, repetition for 3 times a week. Result: The result of Self- correction \& Task Oriented Exercise and Klapp Exercise intervention before and after used paired t-test, got p value 0.0001 . The result of test of difference of influence of intervention given was done by independent t-test, got $p$ value 0,699. Conclusion: There was a significant influence on both interventions, but no difference influence between the two interventions. 


\section{Keywords: Scoliosis, Self correction, Task Oriented Exercise, Klapp Exercise PENDAHULUAN}

Pada anak dan remaja, sekolah memiliki peran pada proses pertumbuhan dan perkembangan (Blewitt, 2010). Dengan meningkatnya teknologi dan tuntutan pemahaman ilmu pengetahuan, mereka diharuskan belajar dengan giat(Syazwan A., 2009).Di sekolah, anak menghabiskan $30 \%$ waktunya dengan posisi duduk (Syazwan A., 2009).Posisi duduk, antara 4-7 jam, bila dengan tempat duduk yang tidak ergonomis, dapat menyebabkan ketegangan otot dan perubahan postur pada tulang belakang (Wiyarno, 2012).Pada konteks ini, telah banyak studi yang mengidentifikasi pola postural pada anak sekolah, dan hasilnya terdapat prevalensi yang tinggi pada perubahan kearah anteroposterior dan lateral pada spinal colum yang disebut skoliosis (De Vasconcelos GA, 2010).

Skoliosis merupakan gangguan akibat disfungsi dan deformitas muskuloskeletal pada bagian tulang belakang, dimana terjadi deviasi postural yang disebabkan oleh banyak hal, dengan ciri-ciri terdapat kurva lateral pada bidang frontal yang dapat berkaitan dengan rotasi transversal dan sagital(Kadoury S, 2012). Seseorang dengan skoliosis mempunyai kurva miring kesamping dan berbentuk " $\mathrm{C}$ " atau "S"(Y Zheng, 2016).Skoliosis dapat diklasifikasikan menjadi kongenital, neuromuskular dan idiopatik (Choudry, 2016). Skoliosis idiopatik paling banyak terjadi pada anak di sekitar masa remaja dengan rentan usia 10-15 tahun (Deepak AS, 2017).

Menurut WHO, remaja adalah penduduk dengan rentan usia 10-19 tahun. Menurut peraturan Kementrian Kesehatan RI, rentan usia remaja adalah $10-18$ tahun (Infodatin, 2016). sebagian anak mengalami masa awal pubertas antara usia 8-13 tahun untuk perempan dan 9-14 tahun untuk lakilaki(Pulungan, 2013). Adolescent (remaja) merupakan fase transisi pertumbuhan dan perkembangan dari masa anak-anak ke masa dewasa(Csikszentmihalyi, 2017). Pada fase pertumbuhan dan perkembangan, remaja mengalami beberapa perubahan fisik dan adaptasi psikososial, termasuk perubahan berupa bertambahnya ukuran postur(Sedrez JA, 2015).Gangguan muskulokeletal pada anak usia sekolah, disebabkan karena pertumbuhan tulang yang belum matang, sehingga kebiasaan-kebiasaan buruk seperti duduk dengan posisi miring akan mempengaruhi pertumbuhan tubuh dan mengakibatkan masalah pada tulang belakang dan persendian sehingga menyebabkan rasa pegal di beberapa bagian tubuh(Syazwan A., 2009). Ketidaknormalan pada tulang belakang, membuat kurva tidak sejajar, sehingga menyebabkan skoliosis (Y Zheng, 2016)

Di Amerika Serikat, sekitar 2-3\% atau setara 7 juta penduduk mengalami skoliosis. Sebagian besar terjadi pada usia dengan rentang 10 hingga 15 tahun, namun kondisi ini dapat dijumpai juga pada bayi dan dewasa. Perempuan 8 kali lebih banyak mengalami skoliosis dbanding laki-laki (National Scoliosis Foundation, 2016).Di negara-negara Asia, prevalensi skoliosis idiopatik berkisar antara 0.4-7\% (Y Zheng, 2016). Di Kuala lumpur, dari 8966 pelajar dengan rentan usia 13-15 tahun, yang terdiri dari 4381 laki-laki dan 4585 perempuan, 410 pelajar terdeteksi idiopatik skoliosis. Jumlah laki-laki yang terdeteksi sebesar $4.2 \%$ dari $5 \%$ perempuan, dengan $3.5 \%$ di usia 13 tahun, $4 \%$ di usia 14 tahun dan $5.2 \%$ di usia 15 tahun. Sedangkan pada perempuan, $5 \%$ pada usia 13 tahun, $4.9 \%$ usia 14 tahun dan 5\% pada usia 15 tahun (Deepak AS, 2017). Di Indonesia, tepatnya Surabaya, 2.93\% anak dengan rentang usia 916 tahun menalami skoliosis dengan perbandingan laki-laki dan perempuan sebesar $1: 4,7$ (Komang Agung IS, 2017).

Bila tidak ditangani, skoliosis dapat berdampak buruk seperti nyeri punggung kronik, fungsi kardiopulmonal, atau keterbatasan mobilitas (Han, 2015).Abnormalitas ini juga berdampak buruk pada postur tubuh (National Scoliosis Foundation, 2009). Tujuan utama penanganan untuk adolescent adalah menurunkan progresifitas masalah seperti resiko nyeri, disabilitas, resiko gangguan pernapasan, bentuk estetika yang kurang baik, serta kesehatan yang berkaitan dengan kualitas hidup di masa yang akan datang. (Weinstein SL, 2008). Penanganan yang dapat diberikan pada skoliosis berupa observasi, pemberian brace/ortotis, pemberian modalitas, terapi fisik, hingga penanganan invasif seperti operasi (Palealu, 2014).

Sesuai dengan PMK No. 65 Tahun 2015 tentang Standar Pelayanan Fisioterapi, pelayanan fisioterapi melingkupi promotif, preventif, kuratif dan rehabilitatif.Kegiatan 
promotif dan preventif termasuk skrining, memberikan program untuk pengurangan nyeri, program untuk peningkatan fleksibilitas, daya tahan dan keselarasan postur (Kemenkes RI, 2015).Fisioterapi juga memberikan layanan pemeriksaan, pengobatan, dan membantu individu dalam memulihkan kesehatan, dan mengurangi rasa sakit (kuratif dan rehabilitatif) (Kemenkes RI, 2015). Fisioterapi merupakan salah satu penanganan yang dapat diberikan pada kasus skoliosis dengan menerapkan terknik manual terapi dalam berbagai metode, seperti iso-stretching, pilates, woodock, schroth, klapp, posture corrective,spine rotation torque machines, dan masih banyak lagi(Dantas, 2017).

Self-correction merupakan teknik rehabilitatif yang bertujuan untuk mereposisi kurva tulang belakang secara mandiri dengan menggerakan tubuh ke posisi tertentu(Monticone, 2014).Sementara taskoriented exercise merupakan suatu pendekatan yang didasari konsep motor control.Pendekatan ini berfokus pada latihan dengan memberikan tugas fungsional yang spesifik yang melibatkan fungsi neuromuskular dan muskuloskeletal(Kumar C. N., 2015).Self-correction dan task oriented exercise dapat menurunkan deformitas tulang belakang dengan pendekatan neuromotor abilities. Dengan bantuan edukasi, pasien terbiasa dalam menerapkan pengoreksian postur secara mandiri dalam kehidupannya sehari-hari yang dapat membantu pencapaian tujuan latihan(Monticone, 2014)

Klapp exerciseberfokus pada gerakan penguluran dan penguatan postur yang mengalami masalah sehingga menyebabkan skoliosis (Iunes DH, 2010). Rudolph Klapp, penemu metode ini menjelaskan, posisi dalam melakukan stretching dan strengthening otot, sangat mudah dan dapat diterapkan pada kelompok latihan kecil(Iunes DH, 2010). Klapp exercise dapat membangun kekuatan, daya tahan, ketangkasan serta koodinasi, sehingga terjadi aktivasi serabut otot secara keseluruhan dan dapat mengurangi lengkungan pada tulang belakang (Lau, 2013).

Dari hasil penelitian sebelumnya, selfcorrection dan task-oriented exersie terbukti dapat mengurangi deformitas pada tulang belakang lebih baik dibandingkan tradisional terapi (spinal mobilization, strengthening and stretching, serta balance and walking exercise) dengan jangka waktu penelitian 12 bulan(Monticone, 2014). Selain itu, klapp exercise pada penelitian lain terbukti dapat meningkatkan kekuatan dan stabilisasi otot extensor(Dantas, 2017) dan mampu memperkecil derajat skoliosis (Suriani Sari, 2013) dengan jangka waktu penelitian 3 bulan (Dantas, 2017).

Berdasarkan hasil observasi yang telah dilakukan di SMPN negeri 36 kota Bekasi, terdapat 707 siswa kelas VII dan VIII dengan rata-rata usia 12 hingga 14 tahun. Dalam satu kelas, terdeteksi 2-4 anak yang memiliki derajat skoliosis $\geq 5^{0}$. Selain itu, rata-rata meja dan kursi di beberapa kelas masih belum sesuai dengan prototype meja dan kursi yang ergonomis, sehingga saat belajar anak akan duduk dengan posisi yang tidak ergonomis dalam waktu yang cukup lama.

Berdasarkan uraian diatas, peneliti mengadakan penelitian perbandingan pengaruh self-correction dan task oriented exercise dengan klapp exercise terhadap derajat skoliosis siswa SMP dengan skoliosis idiopatik di SMP Negeri 36 Kota Bekasi.

\section{METODE}

\section{Ruang Lingkup Penelitian}

Penelitian ini dilakukan di di SMP Negeri 36 Kota Bekasi selama 3 bulan pada bulan April sampai Juni 2018.

\section{Metode Penelitian}

Jenis penelitian adalah penelitian pre eksperimental dengan rancangan penelitian yang digunakan adalah one group pre and post test design.

Penelitian ini dilakukan untuk mengetahui perbedaan pengaruh Selfcorrection \& Task Oriented Exercise dengan Klapp Exercise terhadap derajat skoliosis siswa SMP dengan skoliosis idiopatik tipe $\mathrm{C}$.

\section{Populasi dan Sampel}

Populasi dalam penelitian ini adalah murid di SMP Negeri 36 Kota Bekasi. Subjek penelitian yang diambil adalah 22 orang sampel yang sesuai dengan kriteria inklusi dalam penelitian dan dibagi menjadi 2 kelompok kelompok I diberikan Self Correction \& Task Oriented Exercise, dan kelompok II diberikan perlakuan Klapp Exercise.

\section{Teknik Sampling}


Dalam penelitian ini menggunaka teknik purposive sampling yaitu memilih sampel berdasarkan kriteria yang telah ditentukan.

Adapun kriteria sampel yang dipilih sebagai berikut:

1. Kriteria inklusi:

a. Siswa/I SMP Negeri 36 Kota Bekasi kelas VII dan VIII

b. Usia 12-14 tahun

c. Terdeteksi mengalami skoliosis tipe $\mathrm{C}$ dengan tes plumb line dan skoliometer dengan derajat skoliosis $5-20^{\circ}$

d. Kooperatif dan mampu menerima instruksi

e. Bersedia menjadi subjek penelitian

2. Kriteria eksklusi:

a. Sedang menjadi subjek di penelitian lain

b. Memiliki penyakit berkaitan dengan system kardiovaskuler dan respirasi

c. Pernah mengalami patah tulang belakang

d. Pernah melakukan operasi pada sumsum tulang belakang.

\section{Analisis Data}

1. Analisa Univariat

Dilakukan untuk mendeskripsikan karakteristik responden, data demografi responden, variabel penelitian yang terdiri dari self correction, task oriented exercise, dan klapp exercise, serta derajat skoliosis dengan penyajian bentuk distribusi frekuensi menggunakan narasi, tabel, dan diagram.

2. Analisa Bivariat

Analisa bivariat yang digunakan adalah uji normalitas data menggunakan Shapiro Wilk Test.Analisis data yang dapat digunakan untuk melihat pengaruh intervensi yang diberikan adalah uji PairedT-test dengan data berdistribusi normal. Menggunakan $\alpha=0,05$. Hipotesis diterima dengan nilai $\mathrm{p}<0,05$ dengan tingkat kepercayaan 95\%.Untuk mengetahui perbandingan pada kedua kelompok, dilakukan uji Independent T-test dengan data terdistribusi normal.

\section{HASIL}

\section{A. Karakteristik Berdasarkan Jenis Kelamin}

Tabel 1 Distribusi Sampel berdasarkan Jenis Kelamin pada Kelompok I (Self Correction Task Oriented Exercise) dan Kelompok II (KlappExercise).

\begin{tabular}{ccccccc}
\multirow{2}{*}{$\begin{array}{c}\text { Jenis } \\
\text { Kelamin }\end{array}$} & \multicolumn{2}{c}{ Klp I } & \multicolumn{2}{c}{ Klp II } & $\begin{array}{c}\text { Tota } \\
1\end{array}$ & $\%$ \\
\cline { 2 - 5 } & F & $\%$ & F & $\%$ & \\
\hline Laki-laki & 5 & 45,5 & 4 & 36,4 & 9 & 41,9 \\
Perempuan & 6 & 54,5 & 7 & 63,6 & 13 & 59,1 \\
Jumlah & 11 & 100 & 11 & 100 & 22 & 100 \\
\hline
\end{tabular}

Berdasarkan tabel di atas, persentase siswa dengan jenis kelamin laki-lakipada kelompok I sebesar 45,5\% (5 orang) sementara siswa perempuan sebesar $54,5 \%$ (6 orang). Pada kelompok II, persentase siswa dengan jenis kelamin laki-laki sebanyak 36,4\% (4 orang) sedangkan perempuan $63,6 \%$ (7 orang). Dari hasil tersebut, dapat disimpulkan siswa perempuan lebih banyak dengan persentase sebesar 59,1\% (13 orang) dibandingkan lakilaki 40,9\%(9 orang).

\section{B. Uji Statistik}

Uji normalitas yang digunakan adalah uji Shapiro Wilk Test. Dari hasil uji, didapatkan data yang terdistribusi normal dengan $p$ value $>\alpha(0,05)$.

Tabel 2 Hasil Uji Normalitas Data

\begin{tabular}{cccl}
\hline & $p$ value & & Keterangan \\
\hline & $\begin{array}{c}\text { Kelompok } \\
\text { I }\end{array}$ & $\begin{array}{c}\text { Kelompok } \\
\text { II }\end{array}$ & \\
\hline Pre & 0,079 & 0,097 & Normal \\
Post & 0,158 & 0.361 & Normal \\
Selisih & 0.609 & 0,165 & Normal \\
\hline
\end{tabular}

Pada kelompok I, didapatkan nilai $p$ value pada pre testsebesar 0,079 , post test sebesar 0,158, dan selisih sebesar 0,609. Pada kelompok II didapat nilai $p$ value pada pre test sebesar 0,097, post test sebesar 0,361, dan selisih sebesar 0,165. Sehingga dari keseluruhan didapat nilai $p$ value $>0,05$ yang berarti keseluruhan data terdistribusi normal.

Uji homogenitas dilakukan untuk mengetahui apakah data yang dihitung memiliki kesamaan atau perbedaan. Uji yang digunakan adalah uji Lavene's Testuntukmemastikan bahwa nilai derajat skoliosis sebelum intervensi sama pada masing-masing kelompok dengan hasil $p$ value lebih dari $(0,05)$ yang menandakan data homogen. 
Tabel 3 Hasil Uji Homogenitas

\begin{tabular}{cc}
\hline \multicolumn{2}{c}{ Lavene's Test } \\
\hline $\mathrm{F}$ & P value \\
\hline 0,627 & 0,841
\end{tabular}

Pada penelitian ini didapatkan $p$ value 0,841 yang berarti $>0,05$ sehingga dapat disimpulkan bahwa data homogen atau tidak ada perbedaan rata-rata ata dapat dikatakan sama antara kelompok perlakuan 1 dan kelompok perlakuan 2 .

\section{Uji Hipotesis}

Untuk menguji hipotesis, dilakukan analisa bivariat untuk mengetahui apakah terdapat perbedaan pengaruh intervensi antara kelompok perlakuan I dan II dalam mengurangi derajat skoliosis. Untuk megetahui pengaruh intervensi di masingmasing kelompok, dilakukan uji paires sample t-test, sedangkan untuk mengetahu perbadingan pengaruh antara keduanya dilakukan uji independent $t$-test. Bila nilai $\mathrm{p}<$ 0,05 maka hipotesis diterima, sendangkan bila nilai $\mathrm{p}>0,05$ maka hipotesis ditolak.

1. Uji Hipotesis I dan II

Pengujian hipotesis I dan II menggunakan paired sample t-test untuk menguji pengaruh intervensi masing-masing kelompok terhadap penurunan derajat skoliosis.

Tabel 4 Hasil Uji Paired Sample T-Test Kelompok I

\begin{tabular}{ccccc}
\hline Variabel & Mean & SD & $\begin{array}{c}\text { CI } \\
95 \%\end{array}$ & $\begin{array}{c}P \\
\text { Value }\end{array}$ \\
\hline $\begin{array}{c}\text { Derajat } \\
\text { Skoliosis }\end{array}$ & 2,00 & 1,183 & $\begin{array}{c}1,205- \\
2,795\end{array}$ & 0,00 \\
$\begin{array}{c}\text { Sebelum- } \\
\text { sesudah }\end{array}$ & & & & \\
\hline
\end{tabular}

Berdasarkan tabel 4 didapatkan nilai $p$ value sebesar 0,001 yang berarti nilai $p$ value $<0,05$. Sehingga dapat disimpulkan bahwa HipotesisI diterima atau terdapat pengaruh self-correction dan task oriented exercise dalam mengurangi derajat skoliosiss.

Tabel 5 Hasil Uji Paired Sample T-Test Kelompok II

$\begin{array}{lllll}\text { Variabel } & \text { Mean } & \text { SD } & \text { CI } & P\end{array}$

\begin{tabular}{ccccc}
\hline & & & $95 \%$ & Value \\
\hline Derajat & 2,182 & 0,982 & $1,522-$ & 0,00 \\
Skoliosis & & & 2,841 & \\
\hline
\end{tabular}

Berdasarkan tabel 5 didapatkan nilai $p$ value sebesar 0,001 yang berarti nilai $p$ value $<0,05$. Sehingga dapat disimpulkan bahwa Hipotesis II diterima atau terdapat pengaruh klapp exercise dalam mengurangi derajat skoliosis.

\section{Uji Hipotesis III}

Pengujian hipotesis IIImenggunakan uji Independent Sample T-testdengan menguji selisih derajat skoliosis sebelum dan sesudah intervensi pada kedua kelompok.Uji ini dilakukanuntuk mengetahui perbedaan pengaruh kelompok I dan II dalam mengurangi derajat skoliosis.

Tabel 6 Hasil Uji Independent T-Test pada

Derajat Skoliosis antara Kelompok I dan II

\section{T-Test for Equality Means}

\begin{tabular}{cccc}
\hline $\mathrm{F}$ & P Value & Lower & Upper \\
\hline 0,243 & 0,699 & 1,149 & 0,785
\end{tabular}

Berdasarkan tabel 6 nilaip value sebesar 0,699 , yang menandakan value $>0,05$. Sehingga dapat dismpulkan bahwa Hipotesis III yang mengatakan terdapat perbedaan pengaruh Self-correction dan task oriented exercise dengan Klapp Exercise terhadap derajat skoliosis pada siswa SMP dengan Idiopatik skoliosis ditolak.

\section{PEMBAHASAN}

Berdasarkan hasil analisa statistik, self correction dan task oriented exercise dapat berpengaruh terhadap derajat skoliosis tipe $\mathrm{c}$. Pemberian self correction dapat berpengaruh karena dengan pemberian intervensi ini terjadi peningkatan kemampuan neuromotorbehavio rdan muscle balance. Dalam prespektif neurofisiologi, active self correction baik dilakukan untuk pembelajaran neuro behavior dalam perbaikan postur (nyatanya perbaikan postur tidak hanya berkaitan dengan anatomi namun juga neuromotor behavior) (Grivas, 2008).Neuromotor behavior merupakan suatu bentuk pendekatan dengan konsep neurlogi yang terjadi secara berulang hingga membentuk kesadaran indiviu untuk 
melakukan suatu hal secara mandiri dengan cara yang sesuai dengan target perlakuannya (Laso, 2015). Dengan pemberian edukasi mengenai posisi ergonomis saat duduk, menulis, hingga memakai tas sekolah, anak terbiasa dalam menerapkan pengoreksian postur secara mandiri dalam kehidupannya sehari-hari, hal ini sangat baik untuk mencegah derajat skoliosis bertambah(Monticone, 2014). Selain itu, terjadi penguluran dan penguatan pada otot trunk dan core. Otot-otot yang mengalami pemendekan pada sisi yang concave mengalami penguluran sedangkan otot yang lemah mengalami penguatan. Sehingga, terjadi keseimbangan otot antara satu sisi dengan sisi yang lain(Murphy K, 2010).

Pemberian Task Oriented Exercise, juga terjadi perbaikan koordinasi dan keseimbangan.dengan penambahan instruksi, fungsi neuromotor control akan meningkat. Anak akan lebih fokus dengan $\mathrm{h}$

al yang harus ia lakukan, sehingga dengan lebih mudah bisa memposisikan postural alignment agar lebih tegak. Dengan menginstruksikan pasien untuk meraih objek yang sejajar, menjadikan pengupayaan diri untuk mensejajarkan panjang lengan agar dapat meraih objek, dengan begitu, terjadi pengkoreksian postur dengan dukungan motor learning. Hal ini di dukung berdasarkan jurnal Marco Monticone, Emilia Ambrosini, Daniele Cazzaniga, Barbara Rocca, dan Simona Ferrante pada tahun 2014 dalam jurnal "Active self-correction and task-oriented exercises reduce spinal deformity and improve quality of life in subjects with mild adolescent idiopathic scoliosis". Pada artikel ini dijelaskan adanya penurunan derajat skoliosis dengan $p$ value $0,001<\alpha(0,05)$ yang menandakan adanya perubahan yang bermakna antara sebelum dan sesudah intervensi Active self-correction dan taskoriented exercise dengan rerata penurunan Cobb angle sebesar $5,3^{\circ}$, dengan derajat sebelum intervensi sebesar $19.3^{\circ}$ dan $14^{0}$ setelah intervensi. Sedangkan penurunan ATR sebesar $3,5^{0}$ dengan rerata sebelum $7,1^{0}$ dan rerata sesudah $4,6^{\circ}$. Penelitian dilakukandalam waktu penelitian 12 bulan.. Dalam penelitian ini juga dijelaskan bahwa Active self-correction dan task-oriented exercisesterbukti lebih baik menurunkan derajat skoliosis dibandingkan traditional exercise.
Kelebihan yang dimiliki self-correction dan task-oriented exercise adalah adanya efek positif latihan dengan meningkatkan spinal abilities dengan memberikan instruksi yang benar sehingga meningkatkan kualitas dalam latihan dan mengajarkan kebiasaan-kebiasaan yang benar sangat penting untuk menjaga postur tetap sehat atau sesuai alignment semaksimal mungkin. Sedangkan dalam jurnal yang ditulis Negrini S, Zaina F, Romano M, Negrini A, dan Parzini S. yang berjudul "Specific exercises reduce brace prescription in adolescent idiopathic scoliosis: a prospective controlledcohort study with worst-case analysis" menjelaskan bahwa task oriented exercise terbukti lebih efektif dalam menurunkan derajat skoliosis dibandingkan dengan terapi secara umum. Kemudian dalam penelitian Zapata K, Parent EC, dan Sucato D. yang berjudul "Immediate effects of scoliosis-specific corrective exercises on the Cobb angle after one week and after one year of practice", self corrective memberikan hasil yang lebih signifikan dalam mengurangi derajat skoliosis dibandingkan dengan rekaxed standing for curve dalam sebuah program latihan. Peningkatan kemampuan latihan dan fleksibilitas spinal dapat memberikan kontribusi lebih dalam menurunkan derajat cobb.

Pada Klapp Exercise, latihan dilakukan selama 40 menit, dengan tiap gerakan berdurasi sekitar 5 menit. Dalam gerakan Klapp Exercise, latihan dilakukan selama terjadi penguluran dan penguatan otot-otot trunk sesuai dengan lokasi lengkungannya. Otot yang memendek mengalami penguluran sedangkan otot yang memanjang mengalami penguatan dengan memperkuat rangsangan pada serabut otot secara efektif danserabut otot dapat di aktivasi secara keseluruhan. Dalam gerakan ini secara garis besar juga terjadi peningkatan daya tahan, ketangkasan serta koodinasi, sehingga terjadi aktivasi serabut otot secara keseluruhan dan dapat mengurangi lengkungan pada tulang belakang (Lau, 2013). Hasil ini didukung dengan penelitian Suriani Sari, Ketut Tirtajasa, dan Sugijanto pada tahun 2013 dengan judul "Swiss Ball Exercise dan Koreksi Postur Tidak Terbukti Lebih Baik dalam Memperkecil Derajat Skoliosis Idiophatik daripada Klapp Exercise dan Koreksi Postur Pada Anak Usia 11 - 13 Tahun”. Pada jurnal ini dijelaskan adanya penurunan derajat 
skoliosis dengan $p$ value $0,001<\alpha(0,05)$ yang menandakan adanya perubahan yang bermakna antara sebelum dan sesudah intervensi Klapp Exercise dengan rerata penurunan selisih sebesar $3,87^{\circ}$, rerata sebelum intervensi yaitu $7,73^{\circ}$ dan setelah intervensi sebesar $3,87^{0}$ dalam waktu penelitian 12 minggu. Kelebihan klapp exercise dalam mengurangi derajat skoliosis yaitu dapat memperkuat rangsangan pada serabut otot secara edektif, sehingga serabut otot dapat diaktivasi secara keseluruhan. Sehingga stabilitas dan kesimetrisan pada otot-otot trunk dan core terbentuk dan berdampak besar dalam memperkuat tulang belakang dan membangun lebih banyak kekuatan, daya tahan, ketangkasan, serya koordinasi hingga lengkungan pada tulang belakang dapat berkurang.

Dalam penelitian Denise H. Iunes, Maria B. B. Cecílio, Marina A. Dozza, Polyanna R. Almeida dalam jurnal yang berjudul "Quantitative photogrammetric analysis of the klapp method for treating idiopathic scoliosis" dijelaskan bahwa klapp execise dapat menurunkan derajat skoliosis yang signifikan dalam 20 kali pertemuan, sedangkan iso stretching membutuhkan 30 kali pertemuan. Hal ini membuktikan bahwa klapp exercise lebih cepat dalam menurunkan derajat skoliosis dibandingkaniso stretching. Metode klappberperan dalam membangun fleksibilitas dan kekuatan jaringan otot dengan eccentric action, yang berfungsi meningkatkan stimulasi motor learning pada otot postural untuk meningkatkan fungsional dan koordinasi gerakan. Hal ini juga dapat meningkatkan kesadaran dalam mengubah posisi menjadi lebih ergonomis, karena meningkatnya kemampuan motor learning yang berdampak pada peningkatan kemampuan kontrol postural.

Berdasarkan hasil uji perbandingan antara Klapp exercise dan Self Correction \& Task Oriented Exercise, didapatkan $p$ value 0,699, hal ini berarti bahwa tidak ada perbedaan hasil yang signifikan antara kelompok Self Correction \& Task Oriented Exercise dan kelompok Klapp Exercise. Hal ini terjadi karena masing masing intervensi memiliki pengaruh yang sama sama kuat terhadap penurunan derajat skoliosis tipe $\mathrm{c}$.

\section{KESIMPULAN DAN SARAN}

Berdasarkan hasil analisis penelitian ini didapatkan kesimpulan bahwa baik Self Correction \& Task Oriented Exercise maupun Klapp Exercise sama-sama dapat menurunkan derajat skoliosis tipe c, dan tidak terdapat perbedaan pengaruh antara intervensi Klapp exercise dan Self Correction dengan intervensi Task Oriented Exercise terhadap penurunan derajat skoliosis tipe C-

Berdasarkan penelitian yang telah dilakukan, peneliti menyimpulkan bahwa:

1. Terjadi penurunan rerata nilai derajat skoliosis sesudah diberikan intervensi Self Correction \&Task Oriented Exercise dengan $p$ value 0,001 sehingga intervensi ini diyakini dapat menurunkan derajat skoliosis idiopatik tipe c

2. Terjadi penurunan rerata nilai derajat skoliosis sesudah diberikan intervensi Klapp Exercise dengan $p$ value 0,001 sehingga intervensi ini diyakini juga dapat menurunkan derajat skoliosis idiopatik tipe $\mathrm{c}$

3. Berdasarkan hasil uji independent t-test, tidak terdapat perbedaan antara kelompok intervensi Self Correction \&Task Oriented Exercise dengan kelompok intervensi Klapp Exercise dengan nilai $\mathrm{p}$ value 0,699 . Kedua intervensi ini sama berpengaruh dalam mengurangi derajat skoliosis idiopatik tipe c.

Saran/rekomendasi yang dapat diberikan berdasarkan hasil penelitian ini adlaah baik Klapp Exercise maupun Self Correction \& Task Oriented Exercise dapat dijadikan salah satu latihan yang dapat diaplikasikan dalam mengurangi derajat skoliosis tipe $\mathrm{C}$ terutama pada adolescent.

\section{DAFTAR PUSTAKA}

Blewitt, B. P. (2010, juni 20). The Role of School in the Social World of Adolescence. Retrieved Januari 13, 2018, from Education.com: ttps://www.education.com/reference/ar ticle/

Choudry, M. N. (2016). The Open Orthopaedics Journal. Adolescent Idiopathic Scoliosis, 143-154.

Csikszentmihalyi, M. (2017, November 30). Adolescence. Retrieved januari 13, 2018, from Encyclopædia Britannica : 
https://www.britannica.com/science/ad olescence

Dantas, D. D. (2017). The Journal of Physical Therapy Science. Klapp method effect on idiopathic scoliosis in adolescents: blind randomized controlled clinical trial, 29: 1-7.

Deepak AS, O. J. (2017). The Clinical Effectiveness of School Screening Programme for Idiopatic Scoliosis in Malaysia. Malaysian Orthopedic Journal, 41-46.

Devasconcelos, G. F. (2010). Postural Evaluation of Vertebral Column in Deaf School Kids from 7 to 21 Years Old. Fisioter Mov, 23:371-80.

Grivas, T. B. (2008). The Conservative Scoliosis Treatment. Amsterdam: IOS.

Han, Y. (2015). Intractable \& Rare Diseases Research. Evaluation of quality of life and risk factors affecting quality of life in adolescent idiopathic scoliosis, 4(1):12-16.

Infodatin. (2016). Situasi Kesehatan Organ Reproduksi Remaja. Jakarta Selatan: Kementrian Kesehatan RI.

Iunes DH, C. M. (2010). Rev Bras Fisioter. Quantitative photogrammetric analysis of the klapp method for treating idiopathic scoliosis, 14(2):133-40.

Kadoury S, L. H. (2012). Classification of three-dimensional thoracic deformities in adolescent idiopathic scoliosis from a multivariate analysis. Eur Spine J, 21: 40-49.

Kemenkes RI. (2015). Peraturan Menteri Kesehatan Republik Indonesia Nomor 65 Tahun 2015 Tentang Standar Pelayanan Fisioterapi. Jakarta.

Komang Agung IS, e. a. (2017). Prevalence Rateof Adolescent Idiopathic Scoliosis:Result of School-Based Screening in Surabaya, Indonesia. Malaysian Orthopedic Journal, 17-22.

Kumar, C. N. (2015). Novel Physiotherapies. A Comparison between Task Oriented and Client-Centred Task-Oriented Approaches to Improve Upper Limb Functioning in People with Sub-Acute Stroke.

Laso, M. e. (2015). Neuro Motot Control and Feed Forward Models of Locomotion in Human. Fronties.

Lau, K. (2013). Pembedahan Skoiosis Lengkap. Amerika Serikat: Kesehatan di Tangan Anda Pte Ltd.

Monticone, M. E. (2014). Active selfcorrection and task-oriented exercises reduce spinal deformity and improve quality of life in subjects with mild adolescent idiopathic scoliosis. Results of a randomised controlled trial. Eur Spine J, 23:1204-1214.

Murphy K, W. C.-W. (2010). Pediatic Rehabilitation Principles and Practice (Fourth Edition): New York. Orthopedic and Musculoskeletal Condition, 397-405.

National Scoliosis Foundation. (2009). Scoliosis Media \& Community Guide. America: the Scoliosis Research Society.

Palealu, J. d. (2014). Jurnal Biomedik (JBM). Rehabilitasi Medik pada Skoliosis, 813.

Pulungan, A. B. (2013, september 10). Masalah Pubertas pada Anak dan Remaja. Retrieved januari 12, 2018, from Ikatan Dokter Anak Indonesia: http://www.idai.or.id

Sedrez, J. A. (2015). Risk factors associated with structural postural changes in the spinal column of children and adolescents. Rev Paul Pediatr, 33(1):72-81.

Syazwan A., I. T. (2009). The Association between Ergonomic Risk Facto, RULA Score and Musculoskeletal Pain among School Children: a Preliminary Result Global. J. Health Sci, (2): 73-84.

Weinstein SL, D. L. (2008). Adolescent idiopathic scoliosis. 371:1527-1537.

Wiyarno, S. d. (2012). Model Bangku Kelas terhadap Respons Keluhan pada 
Siswa. Surabaya: Universitas ADIBUANA.

Y Zheng, e. a. (2016). Prevalence and Determinants of Idiopatic Scoliosis in

Primary School Children in Beitang

Districs, Wuxi, China. 48(6): 547-53. 